\title{
Transoral thyroid and parathyroid surgery via the vestibular approach - a 2020 update
}

\author{
Jonathon O. Russell ${ }^{1}$, Zeyad T. Sahli ${ }^{2}$, Mohammad Shaear ${ }^{1}$, Christopher Razavi ${ }^{1}$, Khalid Ali ${ }^{1}$, Ralph P. Tufano ${ }^{1}$ \\ ${ }^{1}$ Department of Otolaryngology-Head and Neck Surgery, The Johns Hopkins University School of Medicine, Baltimore, MD, USA; ${ }^{2}$ Department of \\ Surgery, The University of Virginia Health System, Charlottesville, VA, USA \\ Contributions: (I) Conception and design: RP Tufano, JO Russell, M Shaear; (II) Administrative support: RP Tufano; (III) Provision of study materials \\ or patients: All authors; (IV) Collection and assembly of data: All authors; (V) Data analysis and interpretation: All authors; (VI) Manuscript writing: \\ All authors; (VII) Final approval of manuscript: All authors. \\ Correspondence to: Ralph P. Tufano, MD, MBA, FACS. Division of Head and Neck Endocrine Surgery - Department of Otolaryngology-Head and \\ Neck Surgery at The Johns Hopkins Hospital, 601 N Caroline St 6242, Baltimore, MD 21287, USA. Email: rtufano@jhmi.edu.
}

\begin{abstract}
Transoral endoscopic thyroidectomy and parathyroidectomy via the vestibular approach (TOET/ PVA or TOETVA-TOEPVA) is the latest remote-access technique employed in the central neck. As the only approach that does not leave any cutaneous incision, (TOET/PVA) has become popular in both the Far East and Western series since its original description in 2015. More than just a "scarless" surgery, (TOET/ PVA) has been associated with a short learning curve, access to the bilateral central neck compartments, few surgical contraindications, minimal complications, and minimal additional instrumentation. To date, more than 2,000 cases have been completed, including more than 400 in North America, demonstrating brisk utilization of a novel technique relative to earlier remote access central neck approaches. Herein, we describe updates that continue to improve the safety and efficacy of the procedure.
\end{abstract}

Keywords: Thyroidectomy; parathyroidectomy; thyroid surgery; TOETVA; TOEPVA; remote-access thyroid surgery; scarless thyroid surgery; transoral thyroid surgery

Submitted Jan 24, 2020. Accepted for publication Feb 17, 2020.

doi: 10.21037 /gs.2020.03.05

View this article at: http://dx.doi.org/10.21037/gs.2020.03.05

\section{Introduction}

For more than 100 years, thyroid surgery has been safely performed via an anterior neck incision (1). This scar heals well in the majority of patients, with generally acceptable cosmetic outcomes. Despite this, nearly $20 \%$ of patients will experience some feelings of self-consciousness years after thyroid surgery, while more than $10 \%$ will consider further treatments such as plastic surgery to improve the appearance of their scars (2). The impact of a cervical incision on the health related quality of life (HRQOL) was found to be similar to the impact of vitiligo, psoriasis, or severe atopic dermatitis in one series (3). Because excellent cosmesis cannot be guaranteed, remote-access thyroid surgery has evolved to address the potential morbidity of an anterior cervical incision (4). Unfortunately, the perception of a scar can vary between patients and surgeons, further impairing the ability of patients to achieve optimal cosmesis (5-7).

Before (TOET/PVA), remote-access thyroid and parathyroid surgery techniques have succeeded in avoiding an anterior neck incision by relocating the cutaneous incision to less conspicuous locations. Common examples include areolar or axillary incisions, which can effectively minimize the cosmetic burden in some patients. Despite the improved local cosmesis, these techniques may be challenging due to unfamiliar dissection planes, longer routes to the central neck, and novel complications. Additionally, a steep learning curve has been demonstrated, with long initial operative times (4). Consequently, the adoption of these alternative techniques was slow, especially in the West (4).

In 2016, Anuwong published the first case series of 60 patients who underwent scarless thyroidectomy via the lower vestibule of the mouth with excellent outcomes (8). 
Table 1 Johns Hopkins' TOETVA inclusion and exclusion criteria

\begin{tabular}{ll}
\hline Inclusion & Exclusion \\
\hline $\begin{array}{l}\text { History of hypertrophic scarring or motivation to avoid an anterior } \\
\text { cervical incision }\end{array}$ & $\begin{array}{l}\text { Poorly differentiated cancer or anaplastic. Involvement of } \\
\text { central neck, lateral neck, or extrathyroidal disease extension } \\
\text { Thyroid diameter } \leq 10 \mathrm{~cm} \text { or thyroid volume } \leq 45 \mathrm{~mL}\end{array}$ \\
$\begin{array}{l}\text { If benign/indeterminate nodule, } \leq 6 \mathrm{~cm} \text { or dominant nodule } \leq 2 \mathrm{~cm} \text { if } \\
\text { Bethesda V/suspicious or confirmed differentiated thyroid cancer } \\
\begin{array}{l}\text { Substernal goiter, grade } 1 \text { or Graves' disease that is controlled with } \\
\text { medical management }\end{array}\end{array}$ & $\begin{array}{l}\text { Preoperative RLN paresis } \\
\end{array}$ \\
\hline
\end{tabular}

TOETVA, transoral endoscopic thyroidectomy vestibular approach.

This came as a result of worldwide efforts to explore an alternative remote-access thyroidectomy approach, specifically by utilizing natural orifice transluminal endoscopic surgery (NOTES) concepts (9-14). The first attempts were discouraging, as the sublingual approach resulted in devastating adverse effects, including hypoglossal nerve injury $(15,16)$. Subsequently, Richmon et al. utilized the oral vestibule as an alternative to the sublingual approach (12) which was ultimately adopted by Anuwong.

Following the initial series, multiple institutions around the world have adopted this new technique with similar results (17-32). Currently, TOETVA, with approximately 900 reported cases, perhaps more than other remote-access techniques, is attracting patients who are interested in avoiding a neck scar $(17,33)$. In the West, the endoscopic approach far exceeds the robotic approach, as the latter requires extended operative time, a longer learning curve and, occasionally, an axillary incision for the fourth arm of the robot (24). This manuscript aims to update the reader on the status of transoral thyroid and parathyroid surgery via the vestibular approach.

\section{Indication and contraindications}

\section{TOETVA}

TOETVA surgical indications and contraindications have evolved since its first description in patients by Anuwong in 2016 (8) and are largely practice or institution specific (34). Fifty-five percent of patients undergoing thyroid and parathyroid surgery-approximately 150,000 patients in the US-are estimated to be eligible for transoral endocrine surgery using the most widely accepted guidelines (35). In this section, we will describe the current TOETVA inclusion and exclusion criteria in the literature. Current TOETVA inclusion and exclusion criteria of our practice are described in Table 1.

TOETVA is intended for carefully selected patients. Primarily, candidates must be motivated to avoid an anterior cervical scar and/or have a history of hypertrophic scarring or keloids. Indications for TOETVA include both benign and malignant conditions. Symptomatic grade I goiter (anterior mediastinum) and Grave's disease can be approached through TOETVA (36). Specific inclusion criteria for thyroid preoperative ultrasonography size and volume and index nodule size vary between different institutions and authors. Thyroid gland size cutoffs include a diameter of $8-10 \mathrm{~cm}(8,37,38)$ or estimated thyroid volume $\leq 45 \mathrm{~mL}$, with a nodule size cutoff between $4-6 \mathrm{~cm}$ among benign or cytologically indeterminate (Bethesda II, III, IV) nodules (30,31,39). For patients with nodules that are suspicious for malignancy (Bethesda $\mathrm{V}$ ) or confirmed welldifferentiated thyroid cancer without evidence of metastasis, a maximum index nodule size of $2 \mathrm{~cm}$ has been utilized, which has been shown to be a safe threshold $(36,40)$. If completion thyroidectomy is necessary, a repeat-TOETVA for the contralateral thyroid gland can be safely performed within 3 weeks. After that window, it may be appropriate to consider completion TOETVA after 6 months $(41,42)$.

Current TOETVA exclusion criteria include lateral neck or extrathyroidal disease extension, pre-operative RLN paresis, prior trans-cervical neck surgery, oral abscesses, or patient intolerance to general anesthesia. Previous transoral neck surgery and neck radiation are not absolute contraindications $(37,43)$. Patient age or body mass index (BMI) are not absolute contraindications to surgery.

\section{Surgeon candidacy}

In addition to careful patient selection, surgeon candidacy is 
of utmost importance for procedure safety. Prior to learning (TOET/PVA), a surgeon must be proficient in the standard procedures of the central neck, including thyroidectomy, parathyroidectomy, and central neck dissection in case of necessary conversion to an open (standard) approach (44). High volume (bare minimum is more than 25 thyroid surgeries per year) surgeons have significantly improved outcomes and decreased costs in comparison to low volume surgeons $(45,46)$ with conventional cervical thyroidectomy, and an adequate volume is required to overcome the learning curve with any new technique. A study by Razavi et al. describing the TOETVA learning curve using operative time as a surrogate concluded that 11 cases were needed for procedural proficiency, which is similar to the 15 case curve described for video-assisted thyroidectomy $(47,48)$. However, this study represented the learning curve of only one surgeon in a high volume tertiary hospital and may not be germane to other settings. Further data to determine a requisite number of open thyroidectomies in order to perform transoral thyroid surgery is not available (44). The surgeon must also demonstrate competence with relevant instrumentation and advanced laparoscopy in order to avoid novel and/or serious complications (44). This requires case observations, cadaveric dissections, and mentored initiation of cases to ensure the safety of this novel procedure (41). In addition to surgeon familiarity, all operating room staff should be familiar with the procedure and their respective roles.

\section{Transoral endoscopic parathyroidectomy vestibular approach (TOEPVA)}

TOEPVA can also be performed for select patients with localized primary hyperparathyroidism (HPT). Those without parathyroid adenoma localization, recurrent or persistent primary HPT, suspected multigland disease, secondary or tertiary HPT, family history of MEN, suspected parathyroid carcinoma, or previous central neck surgery or neck irradiation therapy should be excluded from consideration. Similar to TOETVA, the patient should also be highly motivated for a "scarless" approach. The authors recommend two imaging modalities with concordant findings, usually surgeon performed ultrasound and sestamibi with multi-phase CT, for localization prior to offering TOEPVA. This has shown to have a positive predictive value of up to $99 \%$ for localization (49).

\section{Surgical steps and perioperative consideration}

\section{Perioperative considerations}

After confirming eligibility for transoral thyroid surgery, the patient should be aware of all the potential outcomes of the procedure, including numbness of the lower lip and chin. We also stress that the subcutaneous scar tissue will induce mild symptoms of dysesthesia for some time in the midline chin. Additionally, we stress the possibility of conversion to an open technique if deemed appropriate to ensure safety of the patient and completeness of the procedure, as well as the limitations with regards to oncologic outcomes given the lack of long term oncologic follow up. Surgeondirected ultrasound has a vital role in determining eligibility as well as in surgical planning in clinic and prior to port placement in our practice. Patients should be educated about postoperative care including use of antibiotics, wound care and a suggested set of postoperative exercises to hasten recovery $(50)$.

\section{Intraoperative highlights}

TOETVA surgical developments have been seen in trocar placement and intraoperative neuromonitoring (IONM) use. Three incisions are made in the lower vestibule of the mouth. The midline incision is made just above the inferior labial frenulum with a scalpel as preferred by our group to avoid the risk of lip burn. The other two incisions are made just medial to the the vermillion border near the labial commissure and measures less than $5-\mathrm{mm}$ in length. Chai et al., moved these two incisions lateral/posterior from the canine teeth which have been attributed to less mental nerve injury and tearing of the lip commissures (51).

Recently, our group has also detailed the use of IONM during TOETVA (52). This is performed through a FDAapproved, single use, $230 \mathrm{~mm}$ monopolar probe with a ball tip, connected to the IONM system. This allows the surgeon to identify and evaluate the status of the vagus, recurrent laryngeal, and superior laryngeal nerves without any additional incisions. IONM allows active monitoring during thyroid retraction and dissection. Moreover, it enables ipsilateral RLN evaluation prior to proceeding with contralateral lobectomy during a total thyroidectomy. IONM potential limitations associated with use are its costs, the need for intraoperative instrument exchange, and probe 
availability and disposability. Despite this, IONM increases the confidence of surgeons to perform TOETVA safely, and is strongly encouraged by our group.

For the robotic technique, surgeons may utilize an additional axillary incision to insert the fourth robotic arm for counter-traction and drain insertion if needed. Though it is useful, this contradicts the cutaneous "scarless" principle of the transoral surgery that made our group less enthusiastic about employing the current robotic surgical systems for the transoral thyroid surgery.

\section{Outcomes, limitations and potential complications}

\section{Outcomes}

Our group has recently performed an analysis to determine outcomes of 689 TOETVA patients (34) who have undergone isthmusectomy, lobectomy, subtotal thyroidectomy, or total thyroidectomy, with and without central neck dissection. Of these 689 cases, 683 (99\%) were completed without conversion. Those converted to an open approach were due to uncontrolled bleeding (five cases) and excessive tumor size with evidence of pretracheal nodal metastasis (one case). No published cases of permanent RLN injury, permanent hypoparathyroidism, $\mathrm{CO} 2$ embolism, permanent mental nerve injury with TOETVA, with only one hematoma $(0.1 \%)$ reported. The transoral approach to the neck is classified as 'clean-contaminated' surgery and carries an inherently greater risk of infection than clean transcervical thyroidectomy. However, only one case of neck infection $(0.1 \%)$ has been reported. Other complications include reported oral commissure tears and three cases $(0.4 \%)$ of skin flap burn. Moreover, TOETVA patients had decreased postoperative pain compared with patients undergoing transcervical thyroidectomy in one series (32). No significant difference in length of stay has been described (32).

\section{Limitations}

Similar to other novel surgical techniques, transoral vestibular approach surgery is limited by increased operating time, a notable but reasonable learning curve, unique complications (generally minor, as above), and rigid patient selection criteria. (TOET/PVA) has significantly longer operative times than the conventional transcervical technique in all described case series, perhaps due to port placement and flap dissection (43). The largest series by
Anuwong et al. (32) reported significant differences in mean operative times of 78.6 versus 64.2 minutes for lobectomy via TOETVA and the open approach, respectively, and 135.1 versus 103.3 minutes for total thyroidectomy via TOETVA than the open approach, respectively.

The experience with TOEPVA has been more limited than TOETVA thus far. Sasanakietkul et al.'s 12-patient series from Thailand demonstrated the safety of the procedure while achieving biochemical cure of primary hyperparathyroidism without major complications (53). One temporary recurrent laryngeal neve palsy was reported. Our group has presented our experience with more than 20 cases (54).

\section{Potential complications}

Novel complications associated with transoral vestibular approach surgery include mental nerve injury, chin flap perforation, and oral commissure or inferior labial frenulum tear. Revised positions of vestibular incisions to decrease the incidence of nerve injury have been implemented in some series. Previous reports of the transoral vestibular approach documented a high complication rate (15.6-100\%) for mental nerve injury with use of the robotic-assisted technique due to the $5 \mathrm{~mm}$ incisions in close proximity to the center incisions $(16,55,56)$. Since then, both $5 \mathrm{~mm}$ incisions have been relocated, allowing for greater mobility of the lip and decreasing tension on the mental nerve where it exits the mental foramen.

\section{Discussion and future directions}

Transoral vestibular approach central neck surgery has emerged as a solution for patients who wish to avoid any cutaneous incision (Figure 1). Even as scrutiny of novel operative techniques and the effects that new technologies have on patient outcomes has increased, TOETVA and TOEPVA has spread rapidly as an alternative to open thyroidectomy and other remote-access thyroidectomy techniques.

Still as relatively novel surgical techniques, TOETVA and TOEPVA will likely continue to gain traction as their utilization increases and surgeons become more accustomed and experienced with the techniques. With increased operative use and surgeon experience with this approach, the gap in conventional outcomes between TOETVA and the transcervical approach will likely continue to narrow, with both operative time and the incidence of TOETVAspecific complications diminishing.

Furthermore, with the development of the new da Vinci 

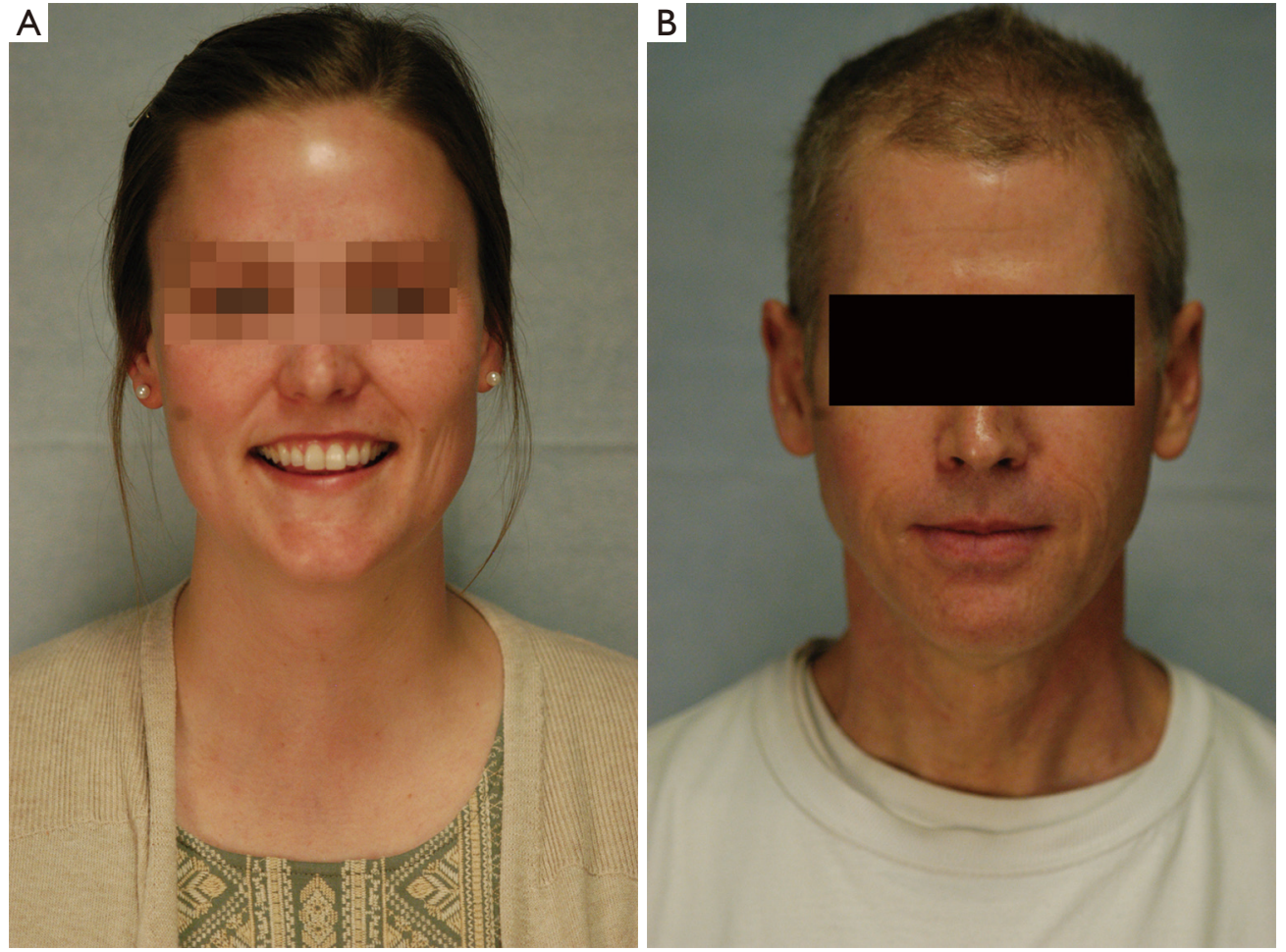

Figure 1 A 31-year-old woman (A) and a 56-year-old man (B) 3 weeks after TOETVA.

single-port robotic system, additional cutaneous incision for an additional surgical arm may no longer be necessary in robotic surgery. Hence, the transoral vestibular approach may be further augmented with robotic surgery to achieve a truly scarless technique that enhances surgical dexterity and subjective surgical performance without compromising the improved cosmesis of TOETVA and TOEPVA (57). Currently, the large size of the central port has limited utilization to some degree.

With increasing experience and utilization of TOETVA and TOEPVA may come expanding indications for other thyroid and parathyroid pathologies. Eligibility criteria for a transoral vestibular approach have continued to expand to include use in well-differentiated thyroid carcinomas, thyroglossal duct cysts, Graves' disease, and sex-affirming chondrolaryngoplasty. Nevertheless, careful adoption is crucial for successful implementation as premature implementation can increase the rate of conversion and hence abandonment of the new technique - and all it has to offer (42).

Although the development and implementation of a transoral vestibular approach for these surgeries may have high initial costs, the payoffs-potential for increased cosmesis, decreased pain, and improved quality-of-life- may mark the next horizon for surgical operative innovation in the neck.

\section{Conclusions}

TOET/PVA is the only surgical technique for thyroid and parathyroid surgery that does not have any cutaneous incision. The rapid adoption to date suggests that further gains may be forthcoming. Future studies are necessary to demonstrate the long-term value of the approach.

\section{Acknowledgments}

The authors thank Emerson Lee for technical help and language editing assistance.

Funding: None.

\section{Footnote}

Conflicts of Interest: All authors have completed the ICMJE uniform disclosure form (available at http://dx.doi. org/10.21037/gs.2020.03.05). Dr. Tufano reports personal fees from Medtronics, personal fees from Hemostatix, 
outside the submitted work. RTP serves as the unpaid editorial board member of Gland Surgery from Sep 2018 to Aug 2020. The other authors have no conflicts of interest to declare.

Ethical Statement: The authors are accountable for all aspects of the work in ensuring that questions related to the accuracy or integrity of any part of the work are appropriately investigated and resolved.

Open Access Statement: This is an Open Access article distributed in accordance with the Creative Commons Attribution-NonCommercial-NoDerivs 4.0 International License (CC BY-NC-ND 4.0), which permits the noncommercial replication and distribution of the article with the strict proviso that no changes or edits are made and the original work is properly cited (including links to both the formal publication through the relevant DOI and the license). See: https://creativecommons.org/licenses/by-nc-nd/4.0/.

\section{References}

1. Latifi R, Rivera R, Gachabayov M, et al. Outcomes of 1,327 patients operated on through twelve multispecialty surgical volunteerism missions: A retrospective cohort study. Int J Surg 2018;60:15-21.

2. Best AR, Shipchandler TZ, Cordes SR. Midcervical scar satisfaction in thyroidectomy patients. The Laryngoscope 2017;127:1247-52.

3. Choi Y, Lee JH, Kim YH, et al. Impact of postthyroidectomy scar on the quality of life of thyroid cancer patients. Ann Dermatol 2014;26:693-9.

4. Berber E, Bernet V, Fahey TJ 3rd, et al. American Thyroid Association Statement on Remote-Access Thyroid Surgery. Thyroid 2016;26:331-7.

5. Arora A, Swords C, Garas G, et al. The perception of scar cosmesis following thyroid and parathyroid surgery: A prospective cohort study. Int J Surg 2016;25:38-43.

6. Goldfarb M, Casillas J. Thyroid Cancer-Specific Quality of Life and Health-Related Quality of Life in Young Adult Thyroid Cancer Survivors. Thyroid 2016;26:923-32.

7. Goswami S, Peipert BJ, Mongelli MN, et al. Clinical factors associated with worse quality-of-life scores in United States thyroid cancer survivors. Surgery 2019;166:69-74.

8. Anuwong A. Transoral endoscopic thyroidectomy vestibular approach: a series of the first 60 human cases. World J Surg 2016;40:491-7.
9. Benhidjeb T, Burghardt J, Stark M. Novel technologies for natural orifice surgery: an overview. Minim Invasive Ther Allied Technol 2008;17:346-54.

10. Benhidjeb T, Wilhelm T, Harlaar J, et al. Natural orifice surgery on thyroid gland: totally transoral video-assisted thyroidectomy (TOVAT): report of first experimental results of a new surgical method. Surg Endosc 2009;23:1119-20.

11. Benhidjeb T, Witzel K, Barlehner E, et al. [The natural orifice surgery concept. Vision and rationale for a paradigm shift]. Chirurg 2007;78:537-42.

12. Richmon JD, Holsinger FC, Kandil E, et al. Transoral robotic-assisted thyroidectomy with central neck dissection: preclinical cadaver feasibility study and proposed surgical technique. J Robot Surg 2011;5:279-82.

13. Richmon JD, Pattani KM, Benhidjeb T, et al. Transoral robotic-assisted thyroidectomy: a preclinical feasibility study in 2 cadavers. Head Neck 2011;33:330-3.

14. Witzel K, von Rahden BH, Kaminski C, et al. Transoral access for endoscopic thyroid resection. Surg Endosc 2008;22:1871-5.

15. Wilhelm T, Harlaar JJ, Kerver A, et al. Surgical anatomy of the floor of the oral cavity and the cervical spaces as a rationale for trans-oral, minimal-invasive endoscopic surgical procedures: results of anatomical studies. Eur Arch Otorhinolaryngol 2010;267:1285-90.

16. Wilhelm T, Metzig A. Endoscopic minimally invasive thyroidectomy (eMIT): a prospective proof-of-concept study in humans. World J Surg 2011;35:543-51.

17. Ahn JH, Yi JW. Transoral endoscopic thyroidectomy for thyroid carcinoma: outcomes and surgical completeness in 150 single-surgeon cases. Surg Endosc 2020;34:861-7.

18. Dionigi G, Lavazza M, Bacuzzi A, et al. Transoral Endoscopic Thyroidectomy Vestibular Approach (TOETVA): From A to Z. Surg Technol Int 2017;30:103-12.

19. Kadem SG, Habash SM, Jasim AH. Transoral Endoscopic Thyroidectomy via Vestibular Approach: A series of the first ten cases in Iraq. Sultan Qaboos Univ Med J 2019;19:e68-72.

20. Kim HK, Kim HY, Chai YJ, et al. Transoral Robotic Thyroidectomy: Comparison of Surgical Outcomes Between the da Vinci Xi and Si. Surg Laparosc Endosc Percutan Tech 2018;28:404-9.

21. Kim HK, Park D, Kim HY. Robotic transoral thyroidectomy: Total thyroidectomy and ipsilateral central neck dissection with da Vinci Xi Surgical System. Head Neck 2019;41:1536-40.

22. Park JO, Anuwong A, Kim MR, et al. Transoral endoscopic 
thyroid surgery in a Korean population. Surg Endosc 2019;33:2104-13.

23. Park JO, Park YJ, Kim MR, et al. Gasless transoral endoscopic thyroidectomy vestibular approach (gasless TOETVA). Surg Endosc 2019;33:3034-9.

24. Razavi CR, Khadem MGA, Fondong A, et al. Early outcomes in transoral vestibular thyroidectomy: Robotic versus endoscopic techniques. Head Neck 2018;40:2246-53.

25. Russell JO, Razavi CR, Al Khadem MG, et al. Anterior cervical incision-sparing thyroidectomy: Comparing retroauricular and transoral approaches. Laryngoscope Investig Otolaryngol 2018;3:409-14.

26. Sivakumar T, Amizhthu RA. Transoral endoscopic total thyroidectomy vestibular approach: A case series and literature review. J Minim Access Surg 2018;14:118-23.

27. Tesseroli MAS, Spagnol M, Sanabria A. Transoral endoscopic thyroidectomy by vestibular approach (TOETVA): initial experience in Brazil. Rev Col Bras Cir 2018;45:e1951.

28. Yi JW, Yoon SG, Kim HS, et al. Transoral endoscopic surgery for papillary thyroid carcinoma: initial experiences of a single surgeon in South Korea. Ann Surg Treat Res 2018;95:73-9.

29. Rege SA, Janesh M, Surpam S, et al. Transoral endoscopic thyroidectomy using vestibular approach: A single center experience. J Postgrad Med 2019;65:81-6.

30. Russell JO, Clark J, Noureldine SI, et al. Transoral thyroidectomy and parathyroidectomy-A North American series of robotic and endoscopic transoral approaches to the central neck. Oral oncology 2017;71:75-80.

31. Kim HY, Chai YJ, Dionigi G, et al. Transoral robotic thyroidectomy: lessons learned from an initial consecutive series of 24 patients. Surg Endosc 2018;32:688-94.

32. Anuwong A, Ketwong K, Jitpratoom P, et al. Safety and outcomes of the transoral endoscopic thyroidectomy vestibular approach. JAMA surgery 2018;153:21-7.

33. Russell JO, Razavi CR, Garstka ME, et al. Remote-Access Thyroidectomy: A Multi-Institutional North American Experience with Transaxillary, Robotic Facelift, and Transoral Endoscopic Vestibular Approaches. J Am Coll Surg 2019;228:516-22.

34. Russell JO, Razavi CR, Shaear M, et al. Transoral vestibular thyroidectomy: current state of affairs and considerations for the future. J Clin Endocrinol Metab 2019;104:3779-84.

35. Grogan RH, Suh I, Chomsky-Higgins K, et al. Patient Eligibility for Transoral Endocrine Surgery Procedures in the United States. JAMA Netw Open 2019;2e194829.
36. Razavi CR, Russell JO. Indications and contraindications to transoral thyroidectomy. Ann Thyroid 2017. doi: 10.21037/aot.2017.10.01

37. Jitpratoom P, Ketwong K, Sasanakietkul T, et al. Transoral endoscopic thyroidectomy vestibular approach (TOETVA) for Graves' disease: a comparison of surgical results with open thyroidectomy. Gland surgery 2016;5:546.

38. Wang Y, Yu X, Wang P, et al. Implementation of intraoperative neuromonitoring for transoral endoscopic thyroid surgery: a preliminary report. J Laparoendosc Adv Surg Tech A 2016;26:965-71.

39. Dionigi G, Tufano RP, Russell J, et al. Transoral thyroidectomy: advantages and limitations. Journal of endocrinological investigation 2017;40:1259-63.

40. Wu YJ, Chi SY, Elsarawy A, et al. What is the appropriate nodular diameter in thyroid cancer for extraction by transoral endoscopic thyroidectomy vestibular approach without breaking the specimens? A surgicopathologic study. Surg Laparosc Endosc Percutan Tech 2018;28:390-3.

41. Anuwong A, Sasanakietkul T, Jitpratoom P, et al. Transoral endoscopic thyroidectomy vestibular approach (TOETVA): indications, techniques and results. Surg Endosc 2018;32:456-65.

42. Razavi CR, Tufano RP, Russell JO. Completion thyroidectomy via the transoral endoscopic vestibular approach. Gland surgery 2018;7:S77.

43. Zhang D, Park D, Sun H, et al. Indications, benefits and risks of transoral thyroidectomy. Best Pract Res Clin Endocrinol Metab 2019;33:101280.

44. Russell JO, Anuwong A, Dionigi G, et al. Transoral thyroid and parathyroid surgery vestibular approach: a framework for assessment and safe exploration. Thyroid 2018;28:825-9.

45. Adam MA, Thomas S, Youngwirth L, et al. Is there a minimum number of thyroidectomies a surgeon should perform to optimize patient outcomes? Ann Surg 2017;265:402-7.

46. Al-Qurayshi Z, Robins R, Hauch A, et al. Association of surgeon volume with outcomes and cost savings following thyroidectomy: a national forecast. JAMA Otolaryngol Head Neck Surg 2016;142:32-9.

47. Razavi CR, Vasiliou E, Tufano RP, et al. Learning curve for transoral endoscopic thyroid lobectomy. Otolaryngol Head Neck Surg 2018;159:625-9.

48. Dionigi G, Boni L, Rovera F, et al. Defining the learning curve for video-assisted thyroidectomy. Int J Surg 2008;6:S1-3.

49. Gawande AA, Monchik JM, Abbruzzese TA, et al. 
Reassessment of parathyroid hormone monitoring during parathyroidectomy for primary hyperparathyroidism after 2 preoperative localization studies. Arch Surg 2006;141:381-4.

50. Navarra G, Bartolo V, Rizzo AG, et al. Pre-and postoperative patient care for transoral thyroidectomy. Ann Thyroid 2018;3:3.

51. Chai YJ, Kim HY, Kim HK, et al. Comparative analysis of 2 robotic thyroidectomy procedures: Transoral versus bilateral axillo-breast approach. Head Neck 2018;40:886-92.

52. Dionigi G, Wu C-W, Tufano RP, et al. Monitored transoral endoscopic thyroidectomy via long monopolar stimulation probe. J Vis Surg 2018;4:24.

53. Sasanakietkul T, Jitpratoom P, Anuwong A. Transoral endoscopic parathyroidectomy vestibular approach: a novel scarless parathyroid surgery. Surg Endosc 2017;31:3755-63.

Cite this article as: Russell JO, Sahli ZT, Shaear M, Razavi C, Ali K, Tufano RP. Transoral thyroid and parathyroid surgery via the vestibular approach-a 2020 update. Gland Surg 2020;9(2):409-416. doi: 10.21037/gs.2020.03.05
54. Razavi CR, Shaear M, Ranganath R, et al. Transoral Endoscopic Parathyroidectomy: Early Outcomes from a North American Series. J Am Coll Surg 2019;229:S83.

55. Nakajo A, Arima H, Hirata M, et al. Trans-Oral VideoAssisted Neck Surgery (TOVANS). A new transoral technique of endoscopic thyroidectomy with gasless premandible approach. Surg Endosc 2013;27:1105-10.

56. Wilhelm T, Wu G, Teymoortash A, et al. Transoral endoscopic thyroidectomy: current state of the art-a systematic literature review and results of a bi-center study. Transl Cancer Res 2016;5:S1521-30.

57. Park D, Shaear M, Chen YH, et al. Transoral robotic thyroidectomy on two human cadavers using the Intuitive da Vinci single port robotic surgical system and CO2 insufflation: Preclinical feasibility study. Head Neck 2019;41:4229-33. 